\title{
The pack as advertisement
}

\author{
John Slade
}

One of the innovations Richard Joshua Reynolds introduced with his Camel brand in 1913 was the coordinated, national advertising campaign. Before Camel, major cigarette makers relied on a wide variety of brands, mainly differing in packaging, to attract customers. The artwork on packs teased and invited. Brand proliferation was the rule, and eye-catching pack design was a key feature. ${ }^{1}$ After Camel, the major companies increasingly focused marketing efforts on a single brand because of the investment necessary to communicate about a brand to a national audience through the mass media. Thus, in the United States, the cigarette epidemic was fuelled, in the main, by just four brands: Camel, Lucky Strike, Chesterfield, and Old Gold.

Brands from a single maker did not begin to multiply again until the 1950 s when the rush to make implied health claims began with the introductions, first, of filtered and later, of "low tar" brands and brand extensions. The next major spur to brand proliferation came in the 1980 s when price competition again appeared in the American market, thanks to the development of "generic" cigarettes by Liggett.

There are now signs of a return to yesteryear, of a renaissance in cigarette pack design.

The cover of this issue of Tobacco Control shows a variety both of limited-edition pack designs for some major brands and some of the niche brands with which major manufacturers are now experimenting.

Four packings of Mild Seven (Japan Tobacco) are aligned along the left border of the cover. At the top are the front and back of a beautiful pack sold in Japan. The bottom two, souvenir packs for returning Japanese tourists, were sold in duty-free shops in Thailand (note the warning) and in the United Kingdom, respectively, in 1995 and 1996.

The series of four Lucky Strike (BAT) packs with "retro" artwork were sold in the Netherlands in 1996.

RJ Reynolds issued four series of Camel "collector's packs" in the United States between 1994 and 1996. Although the first series (of the members of Joe's Hard Pack rock band) had five different designs, the subsequent three have each had 10 different designs. One series depicted the emblematic camel vacationing in 10 different American states, another featured reproductions of early Camel advertising, and the most recent carried a series of Joe Camel advertising themes from the early 1990s. These special packs are put into stores for a brief period and are then gone $\vec{\omega}$ forever. Each retailer is allocated a limited sup- $\vec{\oplus}$ ply of the special packs along with a special countertop display. The packs of the larger $\omega$ series are numbered on the bottom so that the $\overrightarrow{8}$ collector can quickly see if his set is complete. 음

Star, a Philip Morris brand sold in Switzerland, appears on the market in a wide $\infty$ variety of arty pack designs. The pack is $\frac{\mathbb{D}}{0}$ constantly entertaining because it keeps $\frac{D}{3}$ changing. The appeal seems to be that with this brand, one has a different, stylish, contemporary piece of art in one's purse each day.

The cowboy appears on Marlboro 25s. (Philip Morris) sold in the United States. The cowboy on the Lights 25 s packing (not shown) wears the yellow slicker that advertising agency Leo Burnett has made emblematic of Marlboro Lights.

Philip Morris put holograms on limited $\overrightarrow{\overrightarrow{0}}$ numbers of Parliament packs in 1996 as part of 3 a sweepstakes promotion. The holograms depicted tropical scenes thematically tied to the brand's current advertising theme. The 0 hologram on the pack reproduced on the cover shows two tropical fish in the foreground (and $\delta$

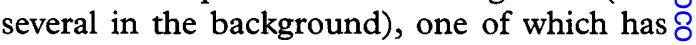
the word "Aruba" inscribed on its side.

Philip Morris has presented Dave's in test markets as a "microsmoke", imitating a fad in $\frac{5}{3}$ the United States for low-production, high-quality beers. It has set up a separate $\mathrm{O}$ company to market the product in a studiedly low-key, self-effacing manner.

RJ Reynolds has taken a somewhat different $\frac{7}{2}$ approach to developing "microsmokes". It also created a new company, Moonlight Tobacco, ${ }^{2} \Omega$ but instead of focusing on only one folksy $N$ brand, the new company churns out numerous novel brands with smart, art deco styling. Illustrated on the cover are Planet ("No additives"), Politix ("Join the party"), and Bee ("Honey-toasted").

In addition, RJR has developed kitschy packings for a relaunch of a brand that has not been on the market for more than 70 years, $\frac{\stackrel{\rho}{\mathbb{D}}}{\unrhd}$
Red Kamel.

What does all this activity in pack design? mean?

As advertising restrictions loom or become을 reality, the surfaces of the pack itself remain available for communication to customers and $\risingdotseq$ potential customers. The increased interest these companies are showing in novel pack designs and in novel brands is likely to be a way of exploring how to market cigarettes in a lim-

\section{Medicine, St Peter's Medical Center, 254 Easton Avenue, New Brunswick, New Jersey email:}

jslade@rci.rutgers.edu 
ited advertising environment. The adaptation of advertising to the pack itself in this manner is but another reason that a requirement for plain packaging is sound public policy. ${ }^{3}$
1 Mullen C. Cigarette pack art. New York: St Martin's Press, 1979.

2 Link E. Novel packs support umbrella marketing. Tobacco 7 Int 1997;2:51-2.

3 Cunningham $\mathrm{R}$, Kyle $\mathrm{K}$. The case for plain packaging. Tobacco Control 1995;4:80-6.

\section{Note to readers}

We hereby solicit your ideas and contributions for future covers of Tobacco Control. As with previous covers, we would like future covers to be colourful and creative-with a tobacco control theme. Original artwork, anti-tobacco posters, photographs, and cartoons may all be considered. Material with an international flavour would be particularly desirable. A cover essay will generally appear in each issue to provide appropriate background information and commentary on the cover.

Please send ideas and submissions (original or high-quality, camera-ready photographs) to the editor at the address on the inside front cover.-ED

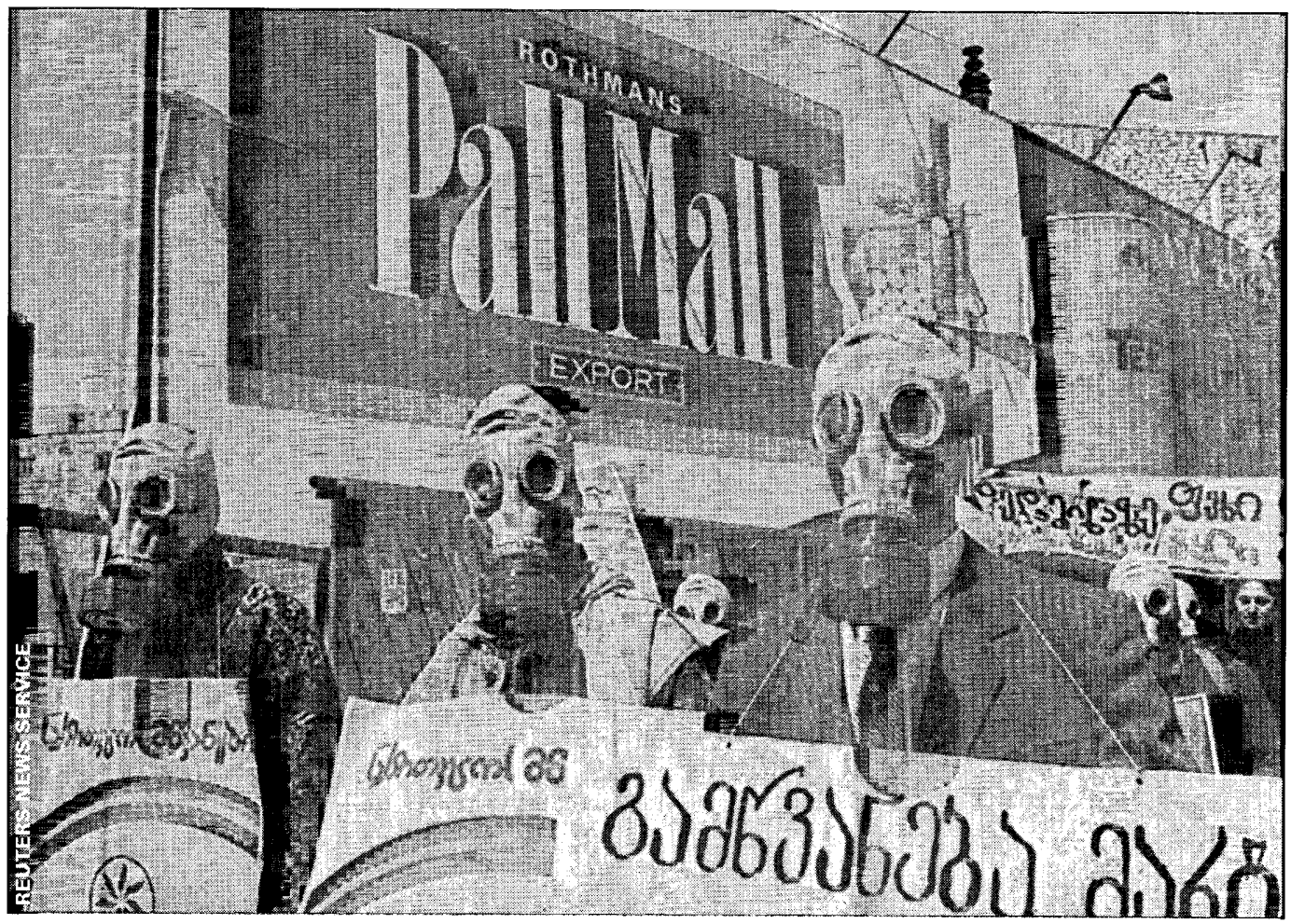

A protest against smoking in Tblisi, Georgia, the former Soviet republic. Source: New York Times, 27 April 1997. 